\title{
Discussion on the Application Value of Doctor-nurse Integrated Mode to the Nursing in the Cardiothoracic Surgery Ling $\mathrm{ZHU}^{1}$ and Ying-ying $\mathrm{ZHANG}^{2, *}$ \\ ${ }^{1}$ Department of Cardiothoracic Vascular Surgery, Renmin Hospital, Hubei University of Medicine, Shiyan, Hubei, China,442000 \\ ${ }^{2}$ Department of Traditional Chinese Medicine, Renmin Hospital, Hubei University of Medicine, Shiyan, Hubei, China,442000 \\ * Corresponding author: hubeiwenbo@qq.com
}

Keywords: Doctor-nurse Integrated Mode, Nursing in the Cardiothoracic Surgery,nursing Satisfaction Degree, Anxiety, Depression, Pain.

\begin{abstract}
Observe the application of doctor-nurse integrated mode to the nursing in the cardiothoracic surgery. Method: take the 130 patients accepting operative treatment in this department from April, 2015 to June, 2017 as the research objects, and divide them into two groups, analysis group and control group with respective 65 cases by double-blind randomizing; take the doctor-nurse integrated mode for the analysis group and conventional nursing intervention for the control group, and summarize and compare the clinical intervention effect of the patients in the two groups. Results: the nursing satisfaction degree of the analysis group was $96.92 \%$ $(63 / 65)$ and that of the control group was $81.54 \%$ (53/65), and the differences of the two groups had statistical significance $(\mathrm{P}<0.05)$; the ratings of self-rating anxiety scale (SAS), self-rating depression scale (SDS) and visual analogue scale (VAS) in the analysis group were much lower than that in the control group after intervention $(\mathrm{P}<0.05)$. Conclusion: the application of doctor-nurse integrated mode to the nursing in the cardiothoracic surgery could had good effect, which was helpful to ease patients' negative emotions and pain at early stage, improve the nursing satisfaction degree, consolidate the treatment effect, and promote postoperative rehabilitation.
\end{abstract}

\section{Introduction}

Cardiothoracic surgery is a modern and comprehensive specialty integrated of medical treatment, scientific research, teaching and prevention, which includes many diseases of cardiac surgery and general thoracic surgery, with operations as main treatment means [1]. However, the operative sites involve many important organs with high complexity and traumatizing, so the people also pay attention to the clinical nursing intervention during the treatment period [2] besides the targeted therapy. In recent years, this department has put the doctor-nurse integrated mode into the perioperative therapy for patients and has achieved satisfactory results. Now we summarize them as follows so as to provide reference for the nursing plan selection in the cardiothoracic surgery.

\section{General Data}

Take the 130 patients accepting operative treatment in this department from April, 2015 to June, 2017 as the research objects, and randomly divide them into two groups, analysis group and control group with respective 65 cases; the control group included 36 male patients and 29 female patients from 30 to 70 years old, and the average age 
was (55.9 \pm 8.2$)$ years old; the analysis group included 34 male patients and 31 female patients from 30 to 70 years old, and the average age was $(56.1 \pm 8.6)$ yeas old; the differences of the general data between the two groups had no statistical significance $(\mathrm{P}>0.05)$.

Inclusion criteria: (1) all patients were eligible for the cardiothoracic surgical operation after examination; (2) the research content was approved by the ethical association of the hospital, and all patients and their family members were in the know to sign the written consents. Exclusion criteria: the people who were $<18$ years old and >70 years old; (2) the people having other systemic diseases and neoplastic lesion on important organs; (3) the people having severe mental diseases.

\section{Method}

Take conventional nursing for the control group, including basic nursing, daily regular inspection, medication instruction, illness monitoring, adjusting patients' mentality, etc.

Take the doctor-nurse integrated mode for the analysis group. The specific content is: (1) daily rounds: make and implement a synchronous rounds system for medical workers, divide them into groups, and each group is composed of the group leader, nurse and sickbed management doctor. Record the patients' state when making the rounds of the wards, know what the patients' needs, and get the advices on the treatment and nursing work. After that, treat patients and record the disease development and untoward effect during the period, complete the text records and feed them back to doctors, and discuss and make treatment and nursing plans together. (2) Improve medical workers' theoretical level: make targeted training schemes such as the participation in the discussion of death cases and intractable cases according to doctor and nurses' knowledge structures, operations and other materials, the practiced nurse practitioners and the doctors in the department shall hold special knowledge lectures weekly to increase nurses' knowledge on the pathogenesis, performance, progress and treatment principle of specialty diseases. Meanwhile, the daily discussion on disease diagnosis and treatment, support and encourage nurses and related doctors to participate in the daily discussion on disease diagnosis and treatment to expand their knowledge scope, so that they can become more careful and reduce faults. (3) doctor-nurse collaborative management: the sickbed management doctor shall cooperate with the primary nurse to carry out all inspection items, and make treatment schemes for the abnormal indexes after discussion and communication. Doctors shall put forward the key points of nursing, and make targeted intervention advices according to key points for joint management.

\section{Observation Indexes}

(1) Take questionnaire to assess the nursing satisfaction degrees of the patients in the two groups after intervention. The total score is $100,>90$ means to bevery satisfied, the scope between 60 to 90 means to be satisfied, and $<60$ means to be not satisfied. Total satisfaction rate $=$ great satisfaction rate + satisfaction rate. (2) Take self-rating anxiety scale (SAS) and self-rating depression scale (SDS) to assess the anxiety and depression performance of the patients in the two groups. The higher the score is, the worse the emotion is. (3) Take visual analogue scale (VAS) to assess patients' pain. The higher the score is, the severer the pain is. 


\section{Statistical Method}

Process all research dada by statistics software (SPSS21.0); when $\mathrm{P}<0.05$, the differences have statistical significance $(\mathrm{P}<0.05)$; take $\mathrm{t}$-test for the measurement data, $\bar{x} \pm s ;$ take $\chi^{2}$ test for the rate of enumeration data.

\section{Results}

\section{Compare the Satisfaction Degrees of the Patients between the two Groups}

The nursing satisfaction degree of the analysis group is $96.92 \%(63 / 65)$ and that of the control group is $81.54 \%$ (53/65), and the differences between the two groups have statistical significance $(\mathrm{P}<0.05)($ table 1$)$.

Table 1. Compare the satisfaction degrees of the patients between the two groups $[n(\%)]$

\begin{tabular}{|c|c|c|c|c|c|}
\hline Grouping & $\begin{array}{l}\text { Number of } \\
\text { cases }\end{array}$ & $\begin{array}{l}\text { Very } \\
\text { satisfied }\end{array}$ & $\begin{array}{l}\text { Satisfie } \\
\text { d }\end{array}$ & $\begin{array}{l}\text { Not } \\
\text { satisfied }\end{array}$ & $\begin{array}{l}\text { Total } \\
\text { satisfaction rate }\end{array}$ \\
\hline $\begin{array}{l}\text { Analysis } \\
\text { group }\end{array}$ & 65 & 39 & 14 & 2 & 96.92 \\
\hline $\begin{array}{l}\text { Control } \\
\text { group }\end{array}$ & 65 & 23 & 30 & 12 & 81.54 \\
\hline$t$ & - & - & - & - & 12.31 \\
\hline $\mathrm{P}$ & - & - & - & - & $<0.05$ \\
\hline
\end{tabular}

The Differences of Two Groups in the Ratings of Emotions and Pain before and after Intervention

The ratings of self-rating anxiety scale (SAS), self-rating depression scale (SDS) and visual analogue scale (VAS) in the analysis group are much lower than that in the control group after intervention $(\mathrm{P}<0.05)$ (table 2$)$.

Table 2. The differences of two groups in the ratings of emotions and pain before and after intervention

$$
(x \pm s)
$$

\begin{tabular}{|c|c|c|c|c|}
\hline \multirow[t]{2}{*}{ Grouping } & \multirow[t]{2}{*}{ Time } & \multicolumn{2}{|c|}{ Emotion rating (scores) } & \multirow{2}{*}{$\begin{array}{ll}\text { VAS } & \text { rating } \\
\text { (scores) } & \end{array}$} \\
\hline & & SAS rating & SDS rating & \\
\hline \multirow[t]{2}{*}{$\begin{array}{l}\text { Analysis } \\
\text { group (65) }\end{array}$} & $\begin{array}{l}\text { Before } \\
\text { intervent } \\
\text { ion }\end{array}$ & $53.5 \pm 6.7$ & $55.7 \pm 6.8$ & $4.1 \pm 0.8$ \\
\hline & $\begin{array}{l}\text { After } \\
\text { intervent } \\
\text { ion }\end{array}$ & $31.6 \pm 5.2 * \#$ & $33.5 \pm 5.4$ *\# & $1.3 \pm 0.3 * \#$ \\
\hline \multirow[t]{2}{*}{$\begin{array}{l}\text { Control } \\
\text { group (65) }\end{array}$} & $\begin{array}{l}\text { Before } \\
\text { intervent } \\
\text { ion }\end{array}$ & $52.9 \pm 7.1$ & $54.3 \pm 7.0$ & $4.0 \pm 0.7$ \\
\hline & $\begin{array}{l}\text { After } \\
\text { intervent } \\
\text { ion }\end{array}$ & $40.4 \pm 5.3 *$ & $42.2 \pm 5.5^{*}$ & $2.2 \pm 0.7 *$ \\
\hline
\end{tabular}

Note: compared with the control group, ${ }^{*}$ means $<0.05$; compared with that after intervention, \# means $<0.05$. 


\section{Discussion}

After cardiothoracic surgery operations, the patients will have short-term negative emotions, such as anxiety and depression, due to their own diseases, limitation of motion, decreasing comfort level and pain, which can influence the recovery directly, and a vicious circle is formed [3]. In addition, there are some contradictions between clinical doctors and nurses. Normally, doctors play a leading role at work and most nurses are assistant and obedient. For example, usually, doctors issue advices and nurses comply with and implement the advices. There is no effective communication between them, and it is difficult to maintain balance, which are the potential factors to trigger contradictions and harmful to clinical work [4, 5].

Doctor-nurse integrated mode is an integrated medical service responsibility system with a team composed of doctors and nurses to provide treatment, nursing, recovery and other medical services. This mode has broken the traditional service structure that the doctor-patient relationship and the nurse-patient relationship are parallel and has realized a new structure integrated of doctors, nurses and patients [6]. In the practice process, nurses shall participate in making the diagnosis and treatment plans, discuss the treatment and nursing schemes together, cooperate with doctors to inspect wards, and discuss cases in group, in order to improve the operating efficiency of all processes based on the traditional nursing. The research results show the nursing satisfaction degree in the analysis group with doctor-nurse integrated mode was 96.92\% (63/65) and that in the control group was $81.54 \%$ (53/65), and the differences between the two groups had statistical significance $(\mathrm{P}<0.05)$; the ratings of self-rating anxiety scale (SAS), self-rating depression scale (SDS) and visual analogue scale (VAS) in the analysis group were much lower than those in the control group after intervention $(\mathrm{P}<0.05)$. Therefore, the application of doctor-nurse integrated mode to the nursing in the cardiothoracic surgery has good effect, which is helpful to improve the patients' negative motivations, ease the pain, consolidate the treatment effect, and improve the nursing satisfaction degree. Its application value is clear [7,8]. After the analysis based on the above conclusion, we think that the doctor-patient relationship, nurse-patient relationship and doctor-nurse relationship will be integrated gradually after implementation of the doctor-nurse integrated mode, and they will complement, replace and cooperate with each other at work, to make the medical treatment process become smooth. In Feng Daixu's discussion on the application of doctor-nurse integrated rounds mode, doctors and nurses shall make the rounds of the wards together, cooperate with each other to analyze patients' overall conditions comprehensively, make and carry out the treatment and nursing plans to provide higher-quality medical services for patients from the different perspectives of doctors and nurses[9]. On the basis of this article, the application of this mode improves the clinical nursing quality and nurses' expertise level, and meets patients' daily needs to the greatest extent based on the implementation of primary nursing to provide important support for building the harmonious relationships among doctors, nurses and patients. Moreover, in the report on the implementation of doctor-nurse integrated mode in primary hospitals written by $\mathrm{Hu}$ Qu'er, Feng Lulu et al, this mode can speed up recovery effectively and reduce medical costs to further reduce treatment costs for patients, to realize real win-win. Therefore, the application scope and development space of this mode are wide [10].

In conclusion, the application of the doctor-nurse integrated mode to the nursing in the cardiothoracic surgery Department has good effect, which is helpful to ease patients' negative emotions and pain at early stage, improve the nursing satisfaction degree, consolidate the treatment effect, and promote postoperative rehabilitation. 


\section{References}

[1] Hirakawa Y, Chiang C, Aoyama A.A qualitative study on barriers to achieving high-quality, community-based integrated dementiacare. J Rural Med,12(1):28-32,(2017).

[2] Lee TJ.Bringing gender sensitivity into sexual health care for women with gynecological cancer.Hu Li Za Zhi, 62(1):16-21,(2015).

[3] Akhtar S, Lee JS.Job burnout: toward an integration of two dominant resource-based models.Psychol Rep,107(1):193-208,(2010).

[4] Busetto L, Luijkx K, Huizing A, Vrijhoef B4.Implementation of integrated care for diabetes mellitus type 2 by two Dutch care groups: a case study.BMC Fam $\operatorname{Pract}(2015)$.

[5] Christensen M.Advancing practice in critical care: a model of knowledge integration.Nurs Crit Care.(2009)

[6] Gerber O.Practitioners' experience of the integration of mental health into primary health care in the West Rand District, South Africa,pp,1-7(2014).

[7] Aletraris L, Roman PM, Pruett J.Integration of Care in the Implementation of the Affordable Care Act: Changes in Treatment Services in a National Sample of Centers Treating Substance Use Disorders.J Psychoactive Drugs,49(2):132-140,(2017).

[8] Hendry A, Taylor A, Improving Outcomes through Transformational Health and Social Care Integration - The Scottish Experience.Healthc Q,19(2):73-79,(2016).

[9] Townsend JA, Bates ML, Rodriguez TE, Andrieu SC, Hagan JL, Cheramie TJ, Smith CA, Leigh JE, Fidel PL Jr.Dental rounds: an evolving process of curriculum integration at the LSU School of Dentistry.J Dent Educ,78(5):796-802,(2014).

[10] Bracco MM,Mafra AC, Abdo AH, Colugnati FA, Dalla MD, Demarzo MM, Implementation of integration strategies between primary care units and a regional general hospital in Brazil to update and connect health care professionals: a quasi-experimental study protocol.BMC Health Serv Res(2016 ). 